\title{
Well-placed bat houses can attract bats to Central Valley farms
}

\author{
by Rachael F. Long, W. Mark Kiser \\ and Selena B. Kiser
}

In an 8-year study from 1997 to 2004, we evaluated the use of 186 bat houses in rural areas of California's Central Valley. We considered the bat houses' size, color, height and location, and found that location was the main factor affecting bat use. Colonies of bats (generally mothers and their young) preferred houses mounted on structures such as buildings, shaded or exposed only to morning sun, and within one-quarter mile of water. In contrast, individual bats (generally males and nonreproductive females) were less selective in where they roosted. The overall occupancy rate for bat houses in our study was $\mathbf{4 8 \%}$ for colonies and $\mathbf{2 8 \%}$ for individual bats. Mexican free-tailed and Myotis bats were the main species using the houses, with occasional sightings of pallid and big brown bats. Bats occupied most houses within the first 2 years of placement.

\section{alifornia is home to 25 species of} bats, seven of which are commonly found in the Central Valley: the Mexican free-tailed bat, big brown bat, pallid bat, California myotis, Yuma myotis, western red bat and hoary bat (table 1). Red and hoary bats tend to roost individually in trees, including orchards, whereas the others form maternity colonies (mothers and their young) in any suitable crevice such as buildings, bridges, trees or rocky outcroppings. Bat maternity colonies in California range in size from less than a hundred for big brown and pallid bats to thousands for Mexican free-tailed and Myotis spp. bats (Zeiner et al. 1990).

Most California bats are insectivorous, with the exception of two desert species in the extreme southern por-

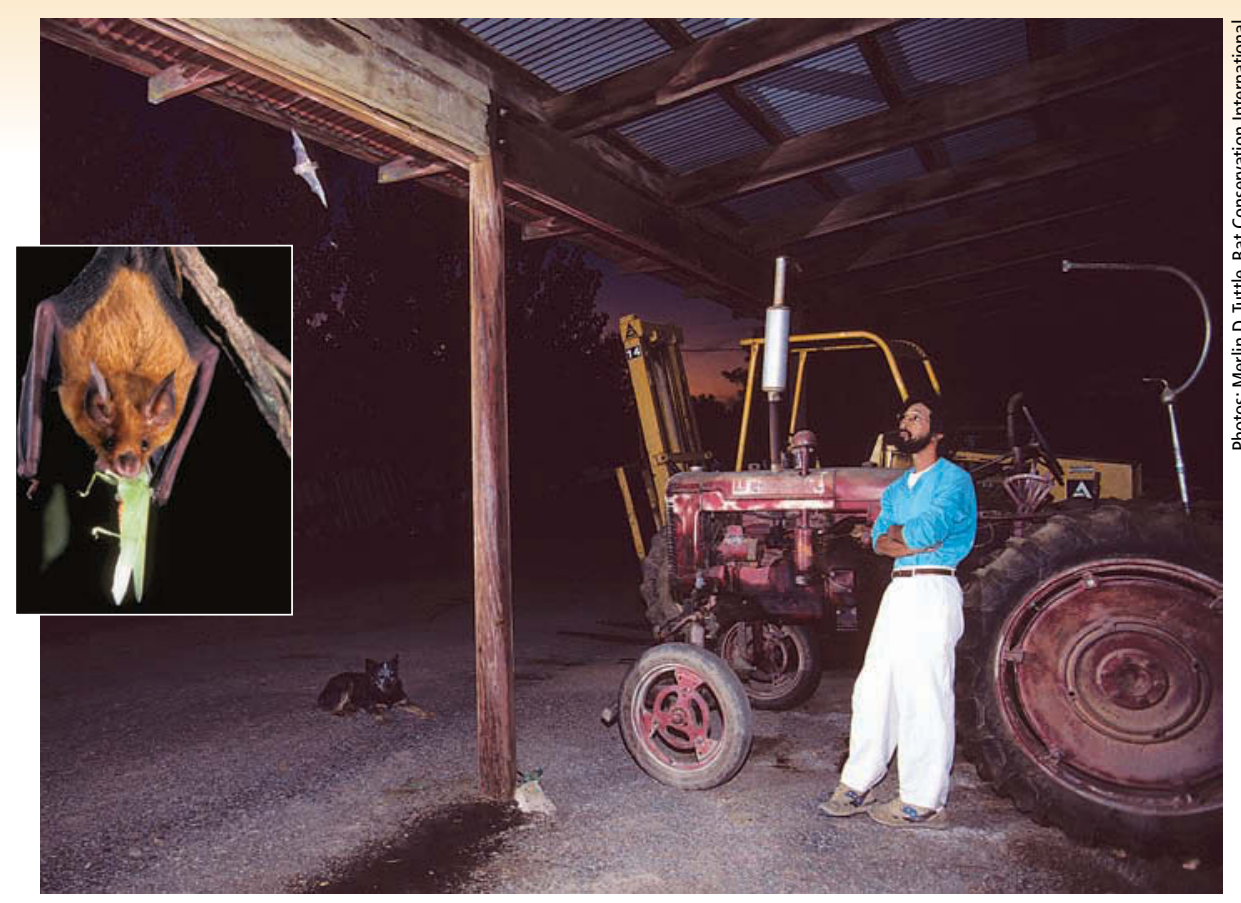

Although the role that insectivorous bats play in agricultural pest control is difficult to quantify, a colony of 150 can consume more than a million insects each year. The authors evaluated how to best attract bat colonies to Central Valley farms. Above, Cliff Fong, an organic grower in Yolo County, watches nocturnal bats in his barn. Inset, a bat eats an insect.

tion of the state that feed on nectar and pollen (Mexican long-tongued bat [Choeronycteris mexicana] and the lesser long-nosed bat [Leptonycteris curasoae]). Insectivorous bats feed on a variety of insects, but different species prefer different prey (Long et al. 1998). For example, big brown bats prefer beetles; hoary and red bats prefer moths; and pallid bats prefer crickets, beetles and scorpions (Whitaker 1995; Zeiner et al. 1990). Bats can consume their body weight or more in insects each night, and a typical colony of 150 bats can eat more than a million insects each year (Whitaker 1995). In the Central Valley, bats tend to hibernate or migrate to warmer areas during the winter when prey is scarce, and return each spring apparently to the same roost to raise their young (Zeiner et al. 1990).

Given the insect-eating nature of bats, farmers may have an interest in attracting them to their farms. Bat houses, akin to bird boxes but with the opening on the bottom, have been used to attract bats since the early 20th century (Campbell 1925; Tuttle et al. 2004). Although bats in many areas of the United States have successfully colonized bat houses, there is limited information on the parameters that make them suitable for use by bat colonies in California's Central Valley.

\section{House design and placement}

The purpose of our research was to evaluate the influence of the design and placement of bat houses on their use as roosting sites by bats in the Central Valley. From 1997 to 2004, 186 bat houses were installed and monitored yearly in 66 rural agricultural locations in California's Central Valley. The houses were constructed using guidelines provided by Bat Conservation International (Tuttle et al. 2004; BCI 2005). Houses were mostly made of plywood with one or more 3/4-inch- to 1-inch-wide chambers that were open at the bottom, allowing bats to fly in and out from below.

The houses were usually caulked and sealed to keep them dark and dry, and most had ventilation slots on the lower sides to prevent overheating. Wooden partitions inside the houses were either roughened or covered with plastic mesh to provide footholds for bats. The houses were categorized as small or 

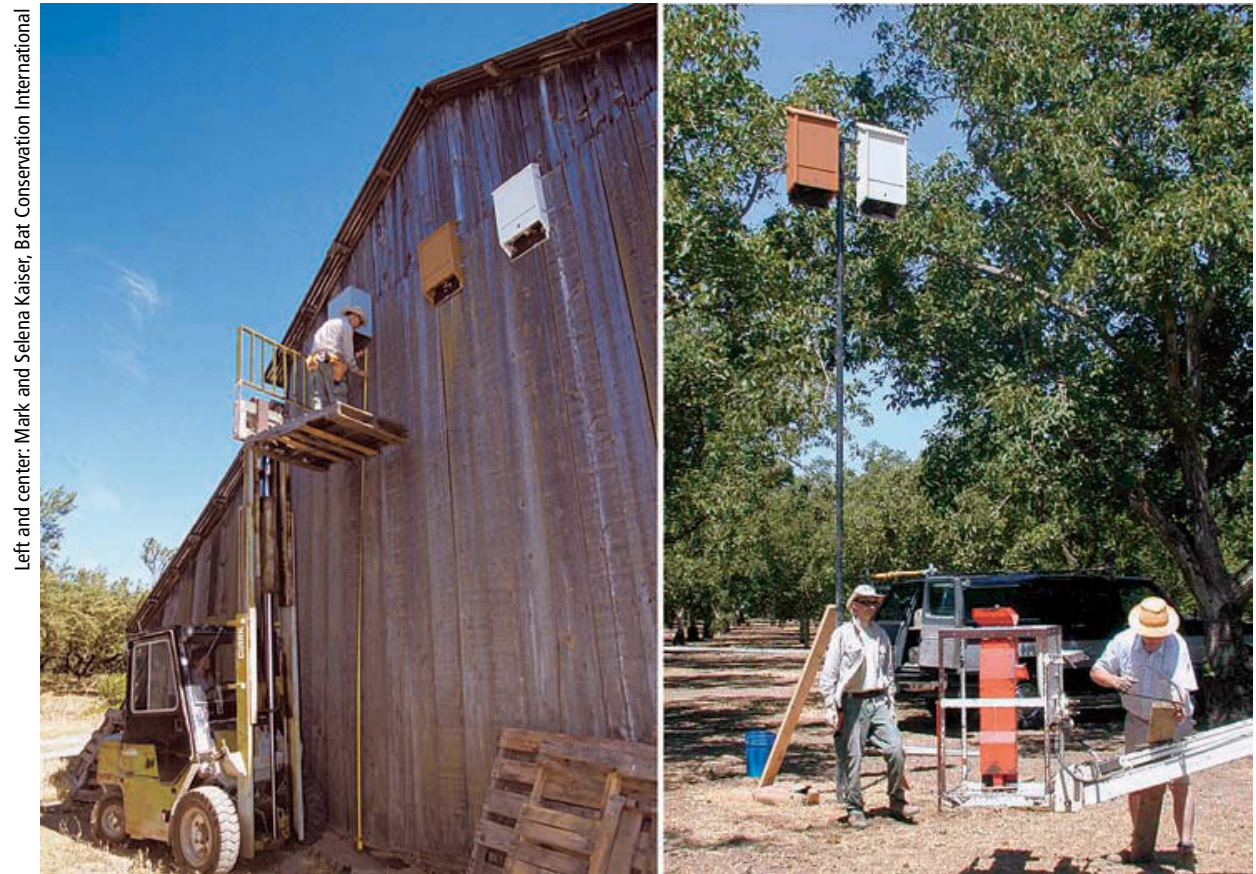

large (less than or greater than 3 linear feet of roost space as measured by the total length [side to side] of all roost chambers combined).

Internal temperature affects bat house occupancy, with females and young preferring houses between $80^{\circ} \mathrm{F}$ and $100^{\circ} \mathrm{F}$ (Tuttle et al. 2004). As a result, we mounted the bat houses in different locations to test the effect of shade or morning sun versus full day or afternoon sun on occupancy rates. Bat houses that received indirect heat through a wall to which they were attached were added to the appropriate category of sun exposure.

In some areas of the United States the color of bat houses influences their internal temperature, and darker houses are recommended for cooler regions and lighter colors for warmer areas (Tuttle et al. 2004). We tested whether color influenced the occupancy of bat houses in the Central Valley by painting them light, medium or dark colors; houses with no sun exposure were excluded from the data analyses.

To test the effect of mount height and type on bat house use, the houses were mounted individually, side-by-side or back-to-back on barns, sheds, poles, bridges or silos between 7 feet and 31 feet off the ground. All houses were at least 6 feet from surrounding objects, such as tree branches or wires, allowing the bats to easily maneuver in and out. In addition, all houses were within 2.5 miles of a permanent water source that was large enough for bats to drink from while on the wing, including canals, ponds and streams. However, because bats apparently favor roosts close to water, bat house occupancy was partitioned into less than and more than one-quarter mile from water (Tuttle et al. 2004).

The bat houses were inspected yearly (usually in June) with a flashlight, and the occurrence, number and species of bats using the houses were recorded. The two species of myotis look so similar that differentiating them would have required us to handle the bats, and we did not want to disturb the maternity colonies. Since bachelors (males and nonreproductive females) tend to roost individually and independently from mothers and their young, we separated our data by the number of bats using the houses. Houses Bats can consume their body weight with five or more bats were labeled as a colony (usually mothers and their young), whereas houses with less than five bats were labeled as individuals (usually males and nonreproductive females).

Data were analyzed using a chisquare distribution to test whether occupancy by both individual bats and colonies of bats depended on bat house height, color, size, mount type, distance to water, sun exposure and time since installation. The observed distributions of occupied bat houses were compared with the available distributions using chi-square contingency

tables, and the power of the tests was calculated according to Cohen (1988).

\section{Bat house occupancy}

The overall occupancy rate for the bat houses was $76 \%$ (48\% for colonies and $28 \%$ for individuals). Out of 141 occupied houses, Mexican free-tailed bats were found in $67 \%$ of the houses, myotis in $26 \%$, pallid bats in $10 \%$ and big brown bats in $2 \%$, with multiple identified due to blocked visibility. We otis, although California myotis could have been present but they have yet to ranged from five to 500 bats per house, or more in insects each night, and a typical colony of 150 bats can eat

with an average size of $64( \pm 10)$ bats. nies of bats reached $64 \%$ in the first 2 years, but declined significantly to $27 \%$ for houses that had been up for more than 4 years without previous use $(P<$ $0.05)$ (fig. 1A). In contrast, individual in time until first occupancy $(P>0.05)$. were no significant differences in the occupancy rates for small versus large

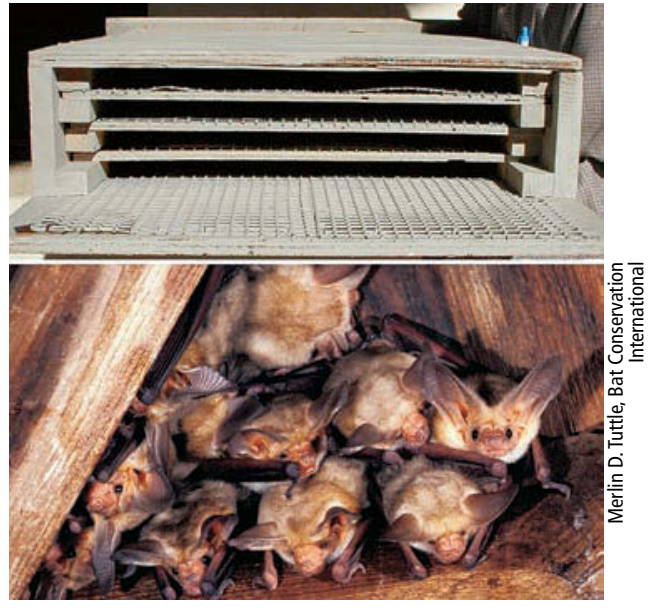

Far left, Mark Kiser of Bat Conservation International installs a bat houses on a barn; left, houses installed on poles were less likely to attract bat colonies than those on barns; top, the inside of a bat house from below; above, a colony of pallid bats. species often sharing roosts (table 1 ). In $24 \%$ of the houses, the bats could not be suspect that the myotis were Yuma mybe identified using bat houses. Colonies more than a million insects each year.

The rate of initial occupancy by colobats exhibited no significant differences For both individuals and colonies, there 
TABLE 1. Characteristics of bats common to California's Central Valley

\begin{tabular}{|c|c|c|c|}
\hline Bats common to the Central Valley & Prey preference & $\begin{array}{c}\text { Bat house occupancy* } \\
\text { by species (\%) }\end{array}$ & $\begin{array}{l}\text { Primary roosting } \\
\text { behavior }\end{array}$ \\
\hline $\begin{array}{l}\text { Mexican free-tailed bat } \\
\text { (Tadarida brasiliensis) }\end{array}$ & \multirow{2}{*}{$\begin{array}{l}\text { General insect } \\
\text { predatorst }\end{array}$} & 67 & \multirow{3}{*}{$\begin{array}{l}\text { Colony forming } \\
\text { in buildings, trees, } \\
\text { rocky crevices, } \\
\text { caves, mines }\end{array}$} \\
\hline $\begin{array}{l}\text { California myotis (Myotis californicus) } \\
\text { Yuma myotis (M. yumanensis) }\end{array}$ & & 26 & \\
\hline $\begin{array}{l}\text { Pallid bat (Antrozous pallidus) } \\
\text { Big brown bat (Eptesicus fuscus) }\end{array}$ & $\begin{array}{c}\text { Beetles, crickets } \neq \\
\text { Beetles }\end{array}$ & $\begin{array}{r}10 \\
2\end{array}$ & \\
\hline $\begin{array}{l}\text { Western red bat (Lasiurus blossevillii) } \\
\text { Hoary bat (L. cinereus) }\end{array}$ & Moths & $\begin{array}{l}0 \\
0\end{array}$ & $\begin{array}{l}\text { Mostly solitary } \\
\text { in trees, } \\
\text { including orchards }\end{array}$ \\
\hline
\end{tabular}

houses, house color or house height $(P>$ 0.05) (table 2).

However, bat house occupancy rates were significantly influenced by their location (fig. 1B). Colonies were found more often in bat houses on structures than in those on poles (53\% vs. $34 \%$ occupancy, respectively, $P<0.05$ ). In contrast, individuals were found more often in bat houses on poles than in those on structures $(40 \%$ vs. $23 \%$ occupancy, respectively, $P<0.05$ ).

Bat colonies also favored bat houses with shade or morning sun versus those with full or afternoon sun $57 \%$ vs. $37 \%$ occupancy, respectively, $P<0.05$ ) (fig. $1 C)$. In contrast, individual bats were more often found using bat houses with full or afternoon sun versus those with shade or morning sun (39\% vs. $19 \%$ occupancy, respectively, $P<0.05$ ). Colonies also favored houses that were within one-quarter mile of a permanent water source over those located farther away (59\% vs. $34 \%$ occupancy, respectively, $P<0.05)$, with no such differences observed for individual bats $(P>$ 0.05) (fig. 1D).

\section{Location, location, location}

The results of our study showed that several factors influence the attraction of bats to bat houses in California's Central Valley. Bat colonies favored bat houses mounted on structures such as barns or bridges, with shade or morning sun, and within one-quarter mile of water. In contrast, individual bats were more often found using bat houses on poles and in full or afternoon sun, while proximity to water was not important within the 2.5-mile area considered. The height, color and size of the bat houses had little impact on occupancy rates, especially for colonies. Although bat house size did not affect occupancy in our study, larger houses appear to offer bats more temperature gradients inside the houses and are preferred in other areas of the country (Kiser and Kiser 2004).

Bat colonies likely preferred bat houses attached to structures because these tended to be buffered from temperature fluctuations, which can exceed $30^{\circ} \mathrm{F}$ during the summer months in the Central Valley. This is important for bat pups, which are born helpless and without fur, to help them stay warm when their mothers leave the roosts at night to feed. Moreover, pole-mounted bat houses may have the disadvantage of increasing bat predation because they serve as perches for owls and hawks (author, personal observation).

Bat colonies probably preferred bat houses in the shade or morning sun because those with full or afternoon sun likely get too hot. Central Valley summer temperatures often exceed $100^{\circ} \mathrm{F}$, and the optimum temperature for raising young bats is between $80^{\circ} \mathrm{F}$ and $100^{\circ} \mathrm{F}$ (Kiser and Kiser 2004). However, bats sometimes use south- or east-facing bat houses, particularly in the spring and fall when temperatures are cooler. As a result, it is probably best to place several houses around a farm to optimize roosting sites for bats.

Although there were no differences in occupancy rates as a function of bat house height, it is important to mount houses at least 10 feet off the ground to protect the bats from cats and other predators that can catch them if they fly too close to the ground (Tuttle et al. 2004). Likewise, bat houses should be mounted at least 20 feet from obstacles, such as wires or trees, that could block the entrance or serve as perches for predators including snakes, hawks and
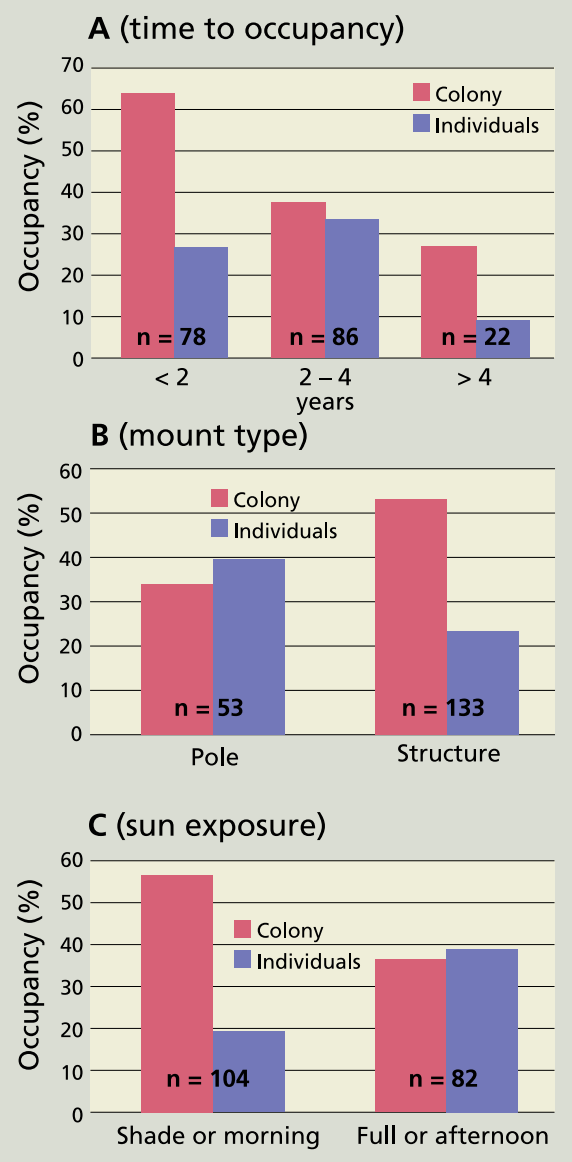

D (distance to water)

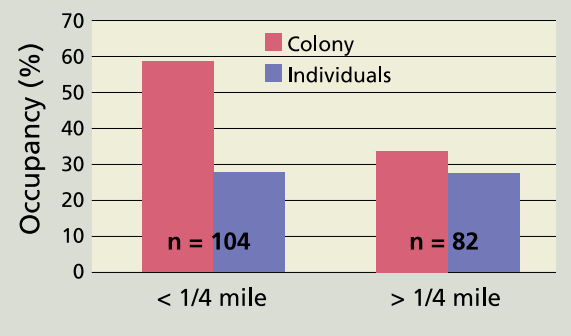

Fig. 1. Bat house occupancy by (A) time to first occupancy in years (from time of installation), (B) mount type, (C) sun exposure and (D) distance to water, by colonies (generally mothers and their young with $\geq$ five bats per house) and individuals (generally males and nonreproductive females with < five bats per house). (A) Colonies were more likely to occupy the houses within the first 2 years of placement $\left(x^{2}=15.1,2 \mathrm{df}, P<0.05, \alpha\right\rangle$ $99 \%$ ) with no such differences observed for individual bats $\left(x^{2}=5.4,2 \mathrm{df}\right.$, NS, $\left.\alpha=99 \%\right)$. (B) Colonies preferred houses mounted on structures (barns, silos, bridges) to those on poles $\left(x^{2}=5.7,1 \mathrm{df}, P<0.05, \alpha=\right.$ ca. $\left.99 \%\right)$; individuals were more often found in houses on poles $\left(x^{2}=5.0,1 \mathrm{df}, P<0.05, \alpha=80 \%\right)$. (C) Colonies preferred houses with shade or morning sun $\left(x^{2}=7.5,1 \mathrm{df}, P<0.05, \alpha>99 \%\right)$; individuals more often used houses with full day or afternoon sun $\left(x^{2}=8.9,1 \mathrm{df}, P<0.05, \alpha\right.$ $>99 \%$ ). (D) Colonies preferred houses within one-quarter mile of water (streams, canals, ponds) $\left(x^{2}=11.0,1 \mathrm{df}, P<0.05, \alpha>99 \%\right)$, with no such differences observed for individuals $\left(x^{2}=0.001,1 \mathrm{df}, \mathrm{NS}, \alpha=44 \%\right)$. 
TABLE 2. Occupancy of bat houses by bat colonies and individuals based on height, color and size

\begin{tabular}{|c|c|c|c|c|}
\hline Parameter & $\begin{array}{l}\text { Number } \\
\text { occupied }\end{array}$ & $\begin{array}{c}\text { Total } \\
\text { number }\end{array}$ & $\begin{array}{c}\text { Chi-square } \\
\text { distribution*, } x^{2}\end{array}$ & $\begin{array}{c}\text { Power at } \\
\alpha=0.05\end{array}$ \\
\hline \multicolumn{5}{|c|}{ Coloniest } \\
\hline \multicolumn{5}{|c|}{ Height (feet) } \\
\hline 7-10 & 6 & 19 & \multirow{4}{*}{$\mathrm{x}^{2}=2.5,3 \mathrm{df}, \mathrm{NS}$} & \multirow{4}{*}{$>99 \%$} \\
\hline $11-15$ & 45 & 91 & & \\
\hline $16-20$ & 28 & 54 & & \\
\hline 21-31 & 10 & 22 & & \\
\hline \multicolumn{5}{|l|}{ Color } \\
\hline Light & 22 & 60 & \multirow{3}{*}{$\mathrm{x}^{2}=2.8,2 \mathrm{df}, \mathrm{NS}$} & \multirow{3}{*}{ ca. $87 \%$} \\
\hline Medium & 6 & 19 & & \\
\hline Dark & 25 & 50 & & \\
\hline \multicolumn{5}{|l|}{ Size§ } \\
\hline Small & 10 & 23 & \multirow{2}{*}{$\mathrm{x}^{2}=0.2,1 \mathrm{df}, \mathrm{NS}$} & \multirow{2}{*}{ ca. $99 \%$} \\
\hline Large & 79 & 163 & & \\
\hline \multicolumn{5}{|c|}{ Individualsף } \\
\hline \multicolumn{5}{|c|}{ Height (feet) } \\
\hline $7-10$ & 4 & 19 & \multirow{4}{*}{$\mathrm{x}^{2}=1.3,3 \mathrm{df}, \mathrm{NS}$} & \multirow{4}{*}{$>95 \%$} \\
\hline $11-15$ & 26 & 91 & & \\
\hline $16-20$ & 14 & 54 & & \\
\hline 21-31 & 8 & 22 & & \\
\hline \multicolumn{5}{|l|}{ Color } \\
\hline Light & 24 & 60 & \multirow{3}{*}{$\mathrm{x}^{2}=4.3,2 \mathrm{df}, \mathrm{NS}$} & \multirow{3}{*}{ ca. $87 \%$} \\
\hline Medium & 4 & 19 & & \\
\hline Dark & 12 & 50 & & \\
\hline \multicolumn{5}{|l|}{ Size§ } \\
\hline Small & 8 & 23 & \multirow[t]{2}{*}{$x^{2}=0.6,1 d f, N S$} & \multirow[t]{2}{*}{$33 \%$} \\
\hline Large & 44 & 163 & & \\
\hline \multicolumn{5}{|c|}{$\begin{array}{l}\text { * Nonsignificant (NS) values for bat house height, color and size show a lack of preference by bats } \\
\text { for differences within these categories. }\end{array}$} \\
\hline \multirow{2}{*}{\multicolumn{5}{|c|}{$\begin{array}{l}\text { † Bat houses with } \geq \text { five bats per house were categorized as a colony (generally mothers and their young). } \\
\text { ‡ Based on visual rating of color intensity; houses with no sun exposure were excluded from the data analyses. }\end{array}$}} \\
\hline & & & & \\
\hline \multicolumn{5}{|c|}{$\begin{array}{l}\text { § Small versus large: less than or greater than } 3 \text { linear feet of roost space (total length, side to side, } \\
\text { of all roost chambers combined). }\end{array}$} \\
\hline ๆ Bat houses V & bats per hou & orized as ind & enerally males and non & ive females). \\
\hline
\end{tabular}

owls. Bat houses should also be placed within a quarter mile from a permanent water source, such a canal, pond or stream; this was favored by bat colonies in our study area as well as elsewhere in the country (Tuttle et al. 2004).

When bat colonies occupied the bat houses in our study, they either showed up as a group, which may have been due to the loss of a roost site, or they started off with a few individuals and slowly increased in numbers. Bat houses were most likely to be occupied by colonies within the first 2 years of placement. Our data suggests that bats either like the houses and move in, or do not and will probably never use them. If houses are not used after 2 to 4 years, our data suggests that they should be moved to new locations.

R.F. Long is UC Cooperative Extension Farm Advisor, Yolo County; and W.M. Kiser and S.B. Kiser are former Conservation Specialists, Bat Conservation
International, Austin, Texas. The authors would like to thank Walter Freeman, Douglas Kelt and Bronwyn Hogan for reviewing this manuscript, the Organic Farming Research Foundation and the many farmers who participated in this study.

\section{References}

[BCI] Bat Conservation International. 2005. www. batcon.org.

Campbell CR. 1925. Bats, Mosquitoes, and Dollars. Boston, MA: Stratford. $262 \mathrm{p}$

Cohen J. 1988. Statistical Power Analysis for the Behavioral Sciences (2nd ed.). Hillsdale, NJ: Lawrence Erlbaum Assoc. $567 \mathrm{p}$

Kiser WM, Kiser SB. 2004. A decade of bat house discovery. Bat House Researcher 12(1):1-7.

Long RF, Simpson T, Ding T, et al. 1998. Bats feed on crop pests in Sacramento Valley. Cal Ag 52(1):8-10.

Tuttle MD, Kiser WM, Kiser SB. 2004. The Bat House Builder's Handbook (2nd ed.). Austin, TX: Univ Texas Pr. $35 \mathrm{p}$.

Whitaker Jr JO. 1995. Food of the big brown bat Eptesicus fuscus from maternity colonies in Indiana and Illinois. Amer Midland Naturalist 134:346-60.

Wilson DE. 1997. Bats in Question: The Smithsonian Answer Book. Washington, DC: Smithsonian Inst Pr. $168 \mathrm{p}$

Zeiner DC, Laudenslayer WF, Mayer KE, et al. (eds.). 1990. California's Wildlife (Vol. 3): Mammals. California Statewide Wildlife Habitat Relationships System. California Department of Fish and Game, Sacramento, CA.
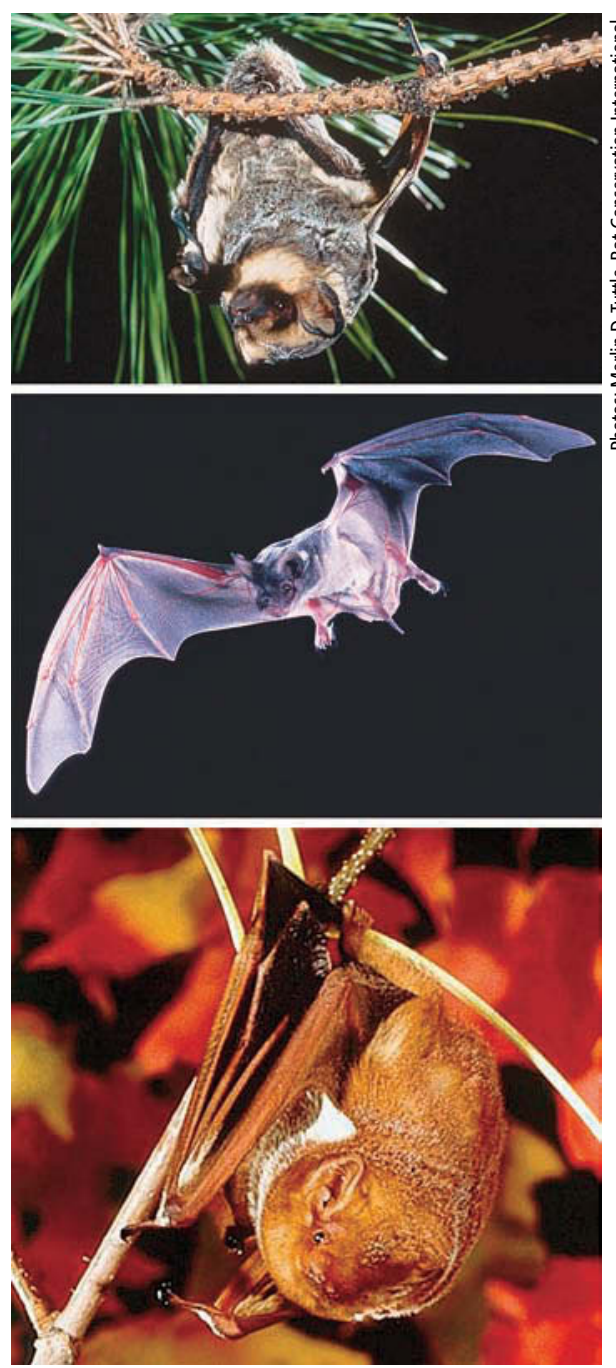

Bats found in California include: top to bottom, hoary bat, Mexican free-tailed bat and red bat.

\section{Rabies prevention}

Although bat rabies is rare in California, it is usually fatal. Bat houses should be placed in areas with minimal human disturbance, because young or sick bats will occasionally fall out of roosts where they may come in contact with people or pets. When putting up a bat house, remind people to leave the bats and bat house alone. If someone handles a bat without gloves or is bitten by a bat, they should seek medical attention immediately. Vaccinating cats and dogs and never touching a bat can almost always prevent rabies (Wilson 1997). 